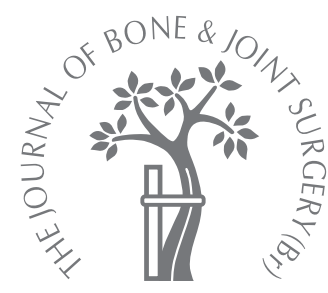

\title{
Role of 2-deoxy-2-[F-18] fluoro-D-glucose positron emission tomography in the management of bone and soft-tissue
} metastases

T. Yanagawa,

T. Shinozaki, Y. Iizuka, K. Takagishi, H. Watanabe

From Gunma University, Gunma, Japan
- T. Yanagawa, MD, PhD, Orthopaedic Surgeon T. Shinozaki, MD, PhD Orthopaedic Surgeon, Associate Professor

Y. lizuka, MD, PhD, Orthopaedic Surgeon K. Takagishi, MD, PhD, Orthopaedic Surgeon,

Professor

Department of Orthopaedic Surgery

H. Watanabe, MD, PhD, Orthopaedic Surgeon, Professor

Physical Therapy

Gunma University School of Health Science, Gunma University Graduate School of Medicine, 3-39-22 Showa, Maebashi, Gunma 371-8511, Japan.

Correspondence should be sent to $\mathrm{Dr}$ T. Yanagawa; e-mail: tyanagaw@med.gunma-u.ac.jp

(C)2010 British Editorial Society of Bone and Joint Surgery doi:10.1302/0301-620X.92B3. $23131 \$ 2.00$

$J$ Bone Joint Surg [Br] 2010;92-B:419-23. Received 22 July 2009; Accepted after revision 17 November 2009

\begin{abstract}
We retrospectively reviewed 71 histopathologically-confirmed bone and soft-tissue metastases of unknown origin at presentation. In order to identify the site of the primary tumour all 71 cases were examined with conventional procedures, including $\mathrm{CT}$, serum tumour markers, a plain radiograph, ultrasound examination and endoscopic examinations, and 24 of the 71 cases underwent 2-deoxy-2-[F-18] fluoro-D-glucose positron emission tomography (FDG-PET). This detected multiple bone metastases in nine patients and the primary site in 12 of the $\mathbf{2 4}$ cases; conventional studies revealed 16 primary tumours. There was no significant difference in sensitivity between FDG-PET and conventional studies.

The mean maximal standardised uptake value of the metastatic tumours was significantly higher than that of the primary tumours, which is likely to explain why FDGPET did not provide better results. It was not superior to conventional procedures in the search for the primary site of bone and soft-tissue metastases; however, it seemed to be useful in the staging of malignancy.
\end{abstract}

Malignant tumours frequently metastasise to bone and pain, neurological disturbance or pathological fracture are often the first symptoms of malignancy. The site of the primary tumour is unknown in approximately $30 \%$ of patients who present with a bony metastasis. ${ }^{1-3}$ The identification of the primary tumour is often costly, time-consuming and difficult, and the site of the primary tumour can remain elusive after thorough and repeated examinations. Carcinoma of unknown primary origin, defined as a histologically-confirmed metastatic tumour of unknown primary site even after detailed medical history, complete physical examinations, blood count and biochemistry, urinalysis and stool occult blood testing, chest radiography, mammography and computed tomography of the abdomen and pelvis, accounts for $3 \%$ to $5 \%$ of all new cancer patients. ${ }^{4-7}$ It is the fourth most common cause of cancer death in both men and women and its prognosis is less than one year. ${ }^{5}$ Consequently, any procedure that can help to localise the site of the primary tumour is of great value.

2-deoxy-2-[F-18] fluoro-D-glucose positron emission tomography (FDG-PET) can be expected to be of help in this regard because FDG, a PET tracer, is an analogue of glucose, the metabolism of which is up-regulated in malignant tumours. ${ }^{8}$ Several authors have reported the usefulness of FDG-PET in the detection of unknown primary tumours, especially in patients with metastatic tumours around the neck. The site of the primary tumour was detected in $30 \%$ to $60 \%$ of carcinoma of unknown primary origin. ${ }^{9-13}$ However, these reports did not focus on tumours that metastasised to the musculoskeletal system. The purpose of this study was to evaluate the role of FDG-PET in staging and detecting the primary origin of bone and soft-tissue metastases.

\section{Patients and Methods}

Patients. Ethical approval for the study was granted from our institution and informed consent was obtained. We retrospectively reviewed 99 patients with histologicallyproven metastases to bone and soft tissue treated in our hospital between 1997 and 2009. These did not include haematopoietic malignancies, such as malignant lymphoma of bone or multiple myeloma, because these usually have no apparent primary site other than in bone. We excluded 28 patients because the primary site of their tumour had already been identified and treated. The remaining 71 patients were studied. There were 49 men and 22 women with a mean age of 64.4 years (19 to 87 ). There were 67 with bone metastases and four with soft-tissue metastases. All 71 cases were examined with conventional procedures, including thoracic, abdominal and 
pelvic CT, serum tumour markers (carcinoembryonic antigen, $\alpha$-fetoprotein, carbohydrate antigen 19-9, carbohydrate antigen 15-3, squamous cell carcinoma-related antigen, cancer antigen 125 , prostate-specific antigen, a plain radiograph of the chest, ultrasound examination of the abdomen and endoscopic examinations. Whole body FDG-PET scanning was carried out on 24 of the 71 patients (16 men, 8 women, mean age 56.9 years (19 to 80$)$ ).

PET studies. Detailed methods for PET scanning have previously been published. ${ }^{14}$ Briefly, for this study, patients fasted for at least six hours before imaging and were investigated with a whole-body PET scanner, SET2400W (Shimazu Corp., Tokyo, Japan) and two PET/CT systems, Biograph 16 (Siemens, Forchheim, Germany), and Discovery ST 16 Lite (GE Yokokawa Medical Systems, Tokyo, Japan). These PET/ CT systems have been used since 2007. A static image, obtained by a simultaneous emission-transmission method with a rotating external source $(68 \mathrm{Ge})$, was initiated $50 \mathrm{~min}$ utes after the injection of $5 \mathrm{MBq} / \mathrm{kg}$ body-weight 18F-FDG synthesised by the cyclotron in Gunma University Hospital. Images were reconstructed using Ramp and Butterworth filters and regions of interest were drawn as described below. For semiquantitative analysis, functional images of the standardised uptake value were produced using attentuationcorrected trans-axial images, the injected dose of FDG, patient body-weight, and the cross-calibration factor between the PET scanner and dose calibrator. Regions of interest $1 \mathrm{~cm}$ in diameter were drawn on the standardised uptake value images over the area corresponding to the tumour to include the site of maximal FDG uptake. Standardised uptake value, a quantitative index of tissue uptake of 18F-FDG, was computed as follows:

Standardised uptake value $=$ radioactive concentration in the tumour $(\mathrm{MBq} / \mathrm{kg}) /$ injected dose $(\mathrm{MBq}) /$ body-weight $(\mathrm{kg})$.

Statistical analysis. The differences in the rate of unknown primary tumours at the final diagnosis between all cases and the cases examined with FDG-PET were analysed using contingency tables and the chi-squared test. The paired $t$-test was used to examine differences in standardised uptake value between primary tumours and metastatic bone tumours. A p-value $<0.05$ was considered significant.

\section{Results}

The conventional studies used to examine all 71 cases revealed the site of the primary in 54 patients $(76.1 \%)$ which included the lung in 20, kidney in ten, prostate in nine, thyroid in five, liver in three, oesophagus in two, pancreas in one, rectum in one, colon in one, retroperitoneal melanoma in one and ovary in one. Post mortem studies identified two further sites (pancreas and rectum); however, the site of the primary tumour in the remaining 15 cases $(21.1 \%)$ remained unknown (Table I).

FDG-PET was used in 24 of the 71 cases (Table II). In the early phase of the study, there was a relatively longer waiting
Table I. Characteristics of the subjects

\begin{tabular}{|c|c|}
\hline & Number \\
\hline \multicolumn{2}{|l|}{ Gender } \\
\hline Male & 49 \\
\hline Female & 22 \\
\hline \multicolumn{2}{|l|}{ Primary site } \\
\hline Lung & 20 \\
\hline Kidney & 10 \\
\hline Prostate & 9 \\
\hline Thyroid & 5 \\
\hline Liver & 3 \\
\hline Oesophagus & 2 \\
\hline Pancreas & 2 \\
\hline Rectum & 2 \\
\hline Colon & 1 \\
\hline Melanoma & 1 \\
\hline Ovary & 1 \\
\hline Unknown & 15 \\
\hline Mean age in yrs (range) & 64.4 (19 to 87 ) \\
\hline \multicolumn{2}{|l|}{ Site of biopsy } \\
\hline \multicolumn{2}{|l|}{ Bone metastasis } \\
\hline Clavicle & 3 \\
\hline Humerus & 5 \\
\hline Radius & 1 \\
\hline Femur & 13 \\
\hline Tibia & 2 \\
\hline Fibula & 1 \\
\hline Sternum & 1 \\
\hline Rib & 4 \\
\hline Cervical spine & 3 \\
\hline Thoracic spine & 15 \\
\hline Lumbar spine & 5 \\
\hline Sacrum & 7 \\
\hline Ilium & 7 \\
\hline \multicolumn{2}{|l|}{ Soft-tissue metastasis } \\
\hline Shoulder & 1 \\
\hline Forearm & 1 \\
\hline Thigh & 1 \\
\hline Lumbar & 1 \\
\hline
\end{tabular}

time for a FDG-PET scan because only one PET scanner was available, however, after two FDG-PET/CT systems were installed in March 2007, most patients could undergo the examination within two weeks. The mean waiting time from a patient's first visit to undergoing FDG-PET was 18.5 days (2 to 76). FDG-PET detected multiple bone metastases in nine cases and a primary site in 12 . In addition, four of the 12 cases showed extraskeletal FDG uptake not only in the primary lesion but also in other organs. Two of these four cases were also detected with abdominal CT and were considered to be thyroid metastases to the liver and mediastinum (case 10) and the colon (case 15), respectively. The other two cases were thought to be false positives because they did not grow or provoke any symptoms as the disease progressed. Conventional studies revealed 16 primary sites, including the lung in six, prostate in two, thyroid in two, kidney in two, rectum in one, colon in one, melanoma in one, and ovary in 
Table II. Patients examined with FDG-PET

\begin{tabular}{|c|c|c|c|c|c|c|c|c|c|c|}
\hline $\begin{array}{l}\text { Patient } \\
\text { No. }\end{array}$ & Gender & $\begin{array}{l}\text { Age } \\
\text { (yrs) }\end{array}$ & $\begin{array}{l}\text { Site of } \\
\text { biopsy }\end{array}$ & $\begin{array}{l}\text { No. of } \\
\text { metastatic } \\
\text { bone lesions }\end{array}$ & $\begin{array}{l}\text { Primary } \\
\text { tumour }\end{array}$ & $\begin{array}{l}\text { Days between first } \\
\text { visit and FDG-PET }\end{array}$ & $\begin{array}{l}\text { SUV }_{\text {max }}^{*} \text { in } \\
\text { the metastatic } \\
\text { lesion }\end{array}$ & $\begin{array}{l}\text { SUV }_{\text {max }} \text { in } \\
\text { the primary } \\
\text { lesion }\end{array}$ & $\begin{array}{l}\text { Procedures that } \\
\text { yidentify the primary } \\
\text { tumour }^{\dagger}\end{array}$ & $\begin{array}{l}\text { FDG positive } \\
\text { sites except } \\
\text { primary }\end{array}$ \\
\hline 1 & $\mathrm{~F}$ & 67 & Rib & Single & Lung & 13 & 2.0 & 2.0 & FDG-PET, biopsy & \\
\hline 2 & $M$ & 44 & Femur & Single & Lung & 14 & 4.4 & 1.4 & CT, FDG-PET & \\
\hline 3 & $\mathrm{M}$ & 37 & Radius & Single & Lung & 30 & 6.8 & 3.5 & CT, FDG-PET, biopsy & \\
\hline 4 & $\mathrm{M}$ & 64 & Ilium & Multiple & Lung & 9 & 11.6 & 6.9 & $X-p, C T$, FDG-PET & Nasal cavity \\
\hline 5 & $M$ & 63 & Ilium & Single & Lung & 29 & 6.4 & 3.0 & $X-p, C T, F D G-P E T$ & Colon \\
\hline 6 & $M$ & 46 & Femur & Single & Lung & 14 & 9.1 & 3.2 & CT, FDG-PET & \\
\hline 7 & $M$ & 69 & Cervical spine & Single & Prostate & 2 & 3.4 & $N A^{\S}$ & Biopsy, PSA & \\
\hline 8 & $M$ & 55 & Ilium & Multiple & Prostate & 16 & 12.3 & 8.5 & FDG-PET, biopsy, PSA & \\
\hline 9 & $\mathrm{~F}$ & 54 & Humerus & Single & Thyroid & 14 & 3.2 & NA & Biopsy & \\
\hline 10 & $\mathrm{~F}$ & 35 & Sacrum & Multiple & Thyroid & 19 & 4.2 & 6.0 & FDG-PET, biopsy & Liver \\
\hline 11 & $M$ & 19 & Sacrum & Single & Kidney & 21 & 8.3 & NA & FDG-PET, biopsy & \\
\hline 12 & $M$ & 80 & Sacrum & Multiple & Kidney & 8 & 5.1 & NC & CT, FDG-PET & \\
\hline 13 & $\mathrm{M}$ & 55 & Sacrum & Multiple & Rectum & 20 & $N C^{\ddagger}$ & NA & CS, FDG-PET & \\
\hline 14 & $\mathrm{~F}$ & 75 & Thoracic spine & Single & Rectum & 29 & NC & 9.4 & Autopsy & \\
\hline 15 & $M$ & 60 & Humerus & Multiple & Colon & 14 & 11.4 & NC & CS, FDG-PET & Mediastinum \\
\hline 16 & $\mathrm{~F}$ & 67 & Humerus & Single & Melanoma & 23 & 5.8 & NA & CT, FDG-PET, biopsy & \\
\hline 17 & $\mathrm{~F}$ & 59 & Ischium & Single & Ovary & 7 & 7.1 & NA & $\mathrm{CT}, \mathrm{MRI}$, ultrasound & \\
\hline 18 & $M$ & 43 & Ilium & Single & Pancreas & 9 & 6.8 & NA & Autopsy & Liver, rectum \\
\hline 19 & $\mathrm{~F}$ & 43 & Ilium & Multiple & Unknown & 5 & 3.4 & NA & & \\
\hline 20 & $\mathrm{~F}$ & 72 & Rib & Multiple & Unknown & 22 & 4.9 & NA & & \\
\hline 21 & $M$ & 68 & Ischium & Single & Unknown & 12 & 3.4 & NA & & \\
\hline 22 & $\mathrm{M}$ & 78 & Femur & Single & Unknown & 11 & 3.5 & NA & & \\
\hline 23 & $M$ & 55 & Thoracic spine & Single & Unknown & 76 & 4.4 & NA & & \\
\hline 24 & M & 57 & Thoracic spine & Multiple & Unknown & 28 & 4.0 & NA & & \\
\hline \multicolumn{11}{|c|}{ * SUV, standardised uptake value } \\
\hline \multicolumn{11}{|c|}{$\begin{array}{l}\text { † PSA, prostate specif } \\
\text { \& NC, not calculated }\end{array}$} \\
\hline
\end{tabular}

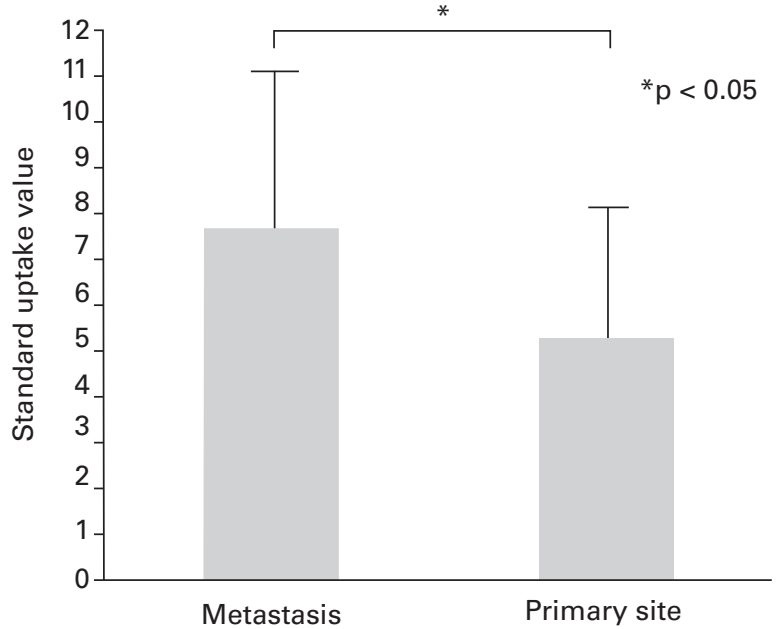

Fig. 1

Mean maximal standardised uptake value of metastatic tumours and primary tumours were 7.65 (SD 3.50) and 5.26 (SD 3.00), respectively, in FDG-PET. The former was significantly higher than the latter $(p=0.0125)$.

one, in the 24 cases, although there was no statistically significant difference in sensitivity between FDG-PET $150.0 \%$, 12 of 24$)$ and conventional studies $(66.7 \%, 16$ of 24$)$. The four cases in which conventional studies revealed the pri- mary site, but FDG-PET did not, included a very small thyroid tumour $(0.7 \mathrm{~cm} \times 0.5 \mathrm{~cm} \times 0.5 \mathrm{~cm})$, a renal cell carcinoma diagnosed as a normal kidney with FDG-PET, and ovary and prostate carcinoma. Meanwhile, FDG-PET could find no primary site in any case that conventional studies could not; in other words, no primary sites of carcinoma of unknown primary origin in metastatic bone tumours were detected with FDG-PET. In six of the 24 cases $(25 \%)$ the primary site remained unknown even after conventional studies, post mortem examination and FDG-PET. There was no significant difference in the rate of unknown primary tumours at final diagnosis between all 71 cases and the 24 cases undergoing FDG-PET (21.1\% vs $25.0 \%)$.

In order to investigate the difference in glucose metabolism between primary and metastatic bone tumours, standardised uptake values were analysed in 10 of 12 cases in which FDG-PET could detect both primary and metastatic tumours. They were not calculated in the remaining two cases. The mean maximal standardised uptake value of metastatic tumours was significantly higher than that of primary tumours (7.65 (2 to 12.3$)$ vs 5.26 (1.4 to 9.4); $\mathrm{p}=0.0125$ paired $t$-test; Fig. 1 ).

\section{Discussion}

Previous reports have shown that the rate of detection of a primary site is $50 \%$ to $90 \%$ for bone metastases in which the primary site is unknown at first diagnosis. ${ }^{1-3,15}$ In the current 
study, conventional procedures detected the primary site in $76.1 \%$ of tumours that metastasised to bone or soft tissue. Several investigations are known to be useful in the search for the primary site of bone metastases. Thoracic and abdominal CT scans are highly recommended and prostatespecific antigen and protein electrophoresis are useful to diagnose carcinoma of the prostate and myeloma, respectively. ${ }^{1,16}$ FDG-PET has been used successfully for the detection of the primary site of carcinoma of unknown primary origin. ${ }^{9-13}$ In the expectation that FDG-PET would improve the detection rate of primary tumours, we examined patients with bone metastases with FDG-PET; unfortunately, however, it did not improve the rate of detection of primary sites.

There are several reasons why FDG-PET might not contribute to the search for the primary site of bone metastases. First, metastatic tumour had a significantly higher mean standardised uptake value than primary tumour suggesting that primary sites are difficult to identify with FDG-PET even if metastasic lesions are obvious. Experimentally, metastasised or invaded malignant tumours are known to be more aggressive than primary tumours ${ }^{16-18}$ and many authors have reported that the higher the pathological grade of skeletal tumour, the higher their standardised uptake value in FDG-PET. ${ }^{19-22}$ Taken together, the difference in aggressiveness between metastatic and primary tumours is reflected in the difference in FDG uptake between them.

Secondly, we performed FDG-PET relatively early, after a mean 18.6 days, which is possibly the cause of the low rate of detection of the primary tumour compared with previous reports. ${ }^{9-13}$ Most of our cases had a FDG-PET scan before the tumours were diagnosed as carcinoma of unknown primary origin, whereas most reports on the usefulness of FDG-PET in identifying a primary site focused on confirmed carcinoma of unknown primary origin. The process of diagnosing a tumour as the latter is as time-consuming as the process required to confirm its primary site and such a time-lag may have disadvantaged FDG-PET in its ability to identify the primary site. Pelosi et $\mathrm{al}^{13}$ reported five carcinomas of unknown primary origin in which the primary site was not found with FDGPET, although subsequent conventional studies performed within three months after the PET scan detected the primary sites, indicating that the timing of the examination is an important factor in identifying the primary site of a tumour of unknown origin.

In our study, the sensitivity of FDG-PET in the identification of primary lesions was $50 \%$ (12 of 24 ), which was not significantly worse than that of conventional procedures $(66.7 \%, 16$ of 24$)$; however, FDG accumulated not only in the primary lesion but also in other organs, including two false-positive cases and two other cases of metastasis. It often accumulates physiologically in the pharynx, intestines, urinary track, and the ovary at menstruation, which may sometimes mislead the physician into performing unnecessary investigations which yield false-positive results and make it difficult to differentiate positive accumulation from over- lapping normal FDG deposits. The physician should evaluate the results of FDG-PET while considering the possibility that physiological FDG accumulation can be an obstacle in the search for primary sites of tumours of unknown origin.

With regard to the staging of malignancies, FDG-PET detected multiple metastases in nine patients and seemed to be very useful in our study as well as those from other authors. ${ }^{23,24}$ Accurate staging is needed to select the appropriate treatment for various malignant tumours and, from this point of view, FDG-PET is still indicated for the investigation of bone metastases from an unknown primary. It can also be used to evaluate the treatment effect by comparing standardised uptake values before and after treatment. Recently, we and other authors concluded that standardised uptake value in FDG-PET after chemotherapy could provide useful prognostic information in patients with primary malignant tumours of bone. ${ }^{25-28}$ Even if the primary lesion remains unknown, bone metastases causing severe pain or fracture should still be treated. In such a situation, the change of standardised uptake values in FDGPET after treatment can be an important clue to evaluate the effect of that treatment.

It seemed difficult to decide when FDG-PET should be performed for patients with bone metastases. If staging is the main purpose, FDG-PET should be performed as soon as possible. Unfortunately, however, there may be a long wait for FDG-PET studies and it is relatively expensive, which may compel physicians to perform conventional studies first. Further studies, including a cost-benefit analysis, are also needed to decide the optimal timing of FDGPET for patients with bone metastases.

We conclude that scanning is no better than more conventional procedures in the search for a primary site in patients with bone or soft-tissue metastases; it hardly contributes to the detection of the origin of a carcinoma of unknown primary origin in bone metastases. However, it has a role in the management of bone and soft-tissue metastases in the search for other metastases and in the evaluation of treatment.

This paper is supported in part by Grants-in-Aid for Young Scientists (B) 20791026 from the Ministry of Education, Culture, Sports, Science and Technology, Japanese Government.

No benefits in any form have been received or will be received from a commercial party related directly or indirectly to the subject of this article.

\section{References}

1. Katagiri H, Takahashi M, Inagaki J, et al. Determining the site of the primary cancer in patients with skeletal metastasis of unknown origin: a retrospective study. Cancer 1999;86:533-7.

2. Nottebaert M, Exner GU, von Hochstetter AR, Schreiber A. Metastatic bone disease from occult carcinoma: a profile. Int Orthop 1989;13:119-23.

3. Shin LY, Chen TH, Lo WH. Skeletal metastasis from occult carcinoma. J Surg Oncol 1992;51:109-13.

4. Abbruzzese JL, Abbruzzese MC, Lenzi R, Hess KR, Raber MN. Analysis of a diagnostic strategy for patients with suspected tumors of unknown origin. J Clin Oncol 1995;13:2094-103

5. Pavlidis N, Briasoulis E, Hainsworth J, Greco FA. Diagnostic and therapeutic management of cancer of an unknown primary. Eur J Cancer 2003;39:1990-2005.

6. Levi F, Te VC, Randimbison L, La Vecchia C. Epidemiology of unknown primary tumours. Eur J Cancer 2002;38:1810-12. 
7. van de Wouw AJ, Janssen-Heijnen ML, Coebergh JW, Hillen HF. Epidemiology of unknown primary tumours: incidence and population-based survival of 1285 patients in Southeast Netherlands, 1984-1992. Eur J Cancer 2002;38:409-13.

8. Warburg 0. On the origin of cancer cells. Science 1956;123:309-14

9. Steve P, Billotey C, Broussolle C, Dumontet C, Mackey JR. The role of 2-deoxy2-[F-18]fluoro-D-glucose positron emission tomography in disseminated carcinoma of unknown primary site. Cancer 2007;109:292-9.

10. Fencl P, Belohlavek 0, Skopalova M, et al. Prognostic and diagnostic accuracy of [18F]FGD-PET/CT in 190 patients with carcinoma of unknown primary. Eur J Nucl Med Mol Imaging 2007;34:1783-92.

11. Nanni C, Rubello D, Castellucci P, et al. Role of 18 F-FDG PET-CT imaging for the detection of an unknown primary tumour: preliminary results in 21 patients. Eur $\mathrm{J} \mathrm{NuCl}$ Med Mol Imaging 2005;32:589-92.

12. Lassen U, Daugaard G, Eigtved A, Damgaard K, Friberg L. 18F-FDG whole body positron emission tomography (PET) in patients with unknown primary tumours (UPT) Eur J Cancer 1999;35:1076-82.

13. Pelosi E, Pennone $\mathbf{M}$, Deandreis $\mathbf{D}$, et al. Role of whole body positron emission tomography/computed tomography scan with 18F-fluorodeoxyglucose in patients with biopsy proven tumor metastases from unknown primary site. O J Nucl Med Mol Imaging 2006;50:15-22

14. Watanabe H, Shinozaki T, Yanagawa T, et al. Glucose metabolic analysis of mus culoskeletal tumours using 18fluorine-FDG PET as an aid to preoperative planning. Bone Joint Surg [Br] 2000;82-B:760-7.

15. Destombe C, Bottom E, le Gal G, et al. Investigations for bone metastasis from an unknown primary. Joint Bone Spine 2007;74:85-9.

16. Asai T, Ueda T, Itoh $K$, et al. Establishment and characterization of a murine osteo sarcoma cell line (LM8) with high metastatic potential to the lung. Int J Cancer 1998;76:418-22

17. Poste G, Doll J, Hart IR, Fidler IJ. In vitro selection of murine $B 16$ melanoma variants with enhanced tissue-invasive properties. Cancer Res 1980;40:1636-44.
18. Poste G, Fidler IJ. The pathogenesis of cancer metastasis. Nature 1980;283:139-46.

19. Dehdashti F, Siegel BA, Griffeth LK, et al. Benign versus malignant intraosseous lesions: discrimination by means of PET with 2-[F-18]fluro-2-deoxy-D-glucose. Radio/ogy 1996;200:243-7.

20. Kern KA, Brunetti A, Norton JA, et al. Metabolic imaging of human extremity musculoskeletal tumors by PET. J Nucl Med 1988;29:181-6.

21. Feldman F, van Heertum R, Manos C. 18FDG PET scanning of benign and malignant musculoskeletal lesions. Skeletal Radio/ 2003;32:201-8.

22. Folpe AL, Lyles RH, Sprouse JT, Conrad EU 3rd, Eary JF. (F-18) fluorodeoxyglucose positron emission tomography as a predictor of pathologic grade and other prognostic variables in bone and soft tissue sarcoma. Clin Cancer Res 2000;6:1279-87.

23. Franzius C, Sciuk J, Daldrup-Link HE, Jurgens H, Schober O. FDG-PET for detection of osseous metastases from malignant primary bone tumours: comparison with bone scintigraphy. Eur J Nucl Med 2000;27:1305-11.

24. Volker T, Denecke T, Steffen I, et al. Positron emission tomography for staging of pediatric sarcoma patients: results of a prospective multicenter trial. J Clin Oncol 2007;25:5435-41.

25. Sato J, Yanagawa T, Dobashi Y, et al. Prognostic significance of $18 \mathrm{~F}-\mathrm{FDG}$ uptake in primary osteosarcoma after but not before chemotherapy: a possible association with autocrine motility factor/phosphoglucose isomerase expression. Clin Exp Metastasis 2008;25:427-35.

26. Hamada K, Tomita Y, Inoue A, et al. Evaluation of chemotherapy response in osteosarcoma with FDG-PET. Ann Nucl Med 2009;23:89-95.

27. Hawkins DS, Schuetze SM, Butrynski JE, et al. [18F]Fluorodeoxyglucose positron emission tomography predicts outcome for Ewing sarcoma family of tumors. $J$ Clin Oncol 2005;23:8828-34

28. Hawkins DS, Conrad EU 3rd, Butrynski JE, Schuetze SM, Eary JF. [F-18]-fluorodeoxy-D-glucose-positron emission tomography response is associated with outcome for extremity osteosarcoma in children and young adults. Cancer 2009;115:3519-25 